\title{
O JORNAL DE FILOLOGIA
}

Erasmo d'Almeida Magalhães

Nota Introdutória

O interesse na obtenção de elementos para poder acompanhar de perto as normas seguidas por diferentes publicações dedicadas à difusão e ao ensino da filologia e da linguíística, como também as não especializadas nestas disciplinas científicas, nos levaram à elaboração de indices de assuntos e de autores. (1)

Assim fazendo, pensámos ter uma visão mais clara e apropriada das "formas de pensar" utilizadas pelos estudiosos das duas disciplinas, correntes no Brasil. E mais, como estas "formas de pensar" contribuíram ou contribuem para as investigações levadas a efeito, tendo em conta o português falado no Brasil, as línguas indígenas do país e a onomástica.

Infelizmente, em nosso país, a vida dos periódicos especialisados nasduas matéria é, em gírande maioria, efêmera. No caso atuam como exceções as revistas Littera, distribuída pela Editora Grifo, Alpha e Revista de Letras, estas duas editadas pela Faculdade de Filosofia, Ciências e Letras de Marília e Assis, respectivamente.

O Jornal de Filosofia foi lançado em 1953, sob direção e orientação do Prof. Francisco da Silveira Bueno, secretariado pelos professores Dinorah da Silveira Pecoraro e José Cretela Júnior. Foram editados cinco volumes, num total de treze números, todos distribuídos pela Editora Saraiva.

Como constava da apresentação do primeiro número, a revista teve por escopo "divulgar estudos de filologia, tomando o vocábulo em seu

(1) - Indices da Revista Ibéria. Revista do Instituto Histórico e Geografico de São Paulo, S. Paulo, vol. LXXXVI, 1975. Indice da Revista Brasileira de Filologia. Revista do Instituto de Estudos Brasileiros, S. Paulo, n 16, 1975. 
vasto sentido. Especialmente, porém, traz em mira as pesquisas feitas no terreno da língua portuguêsa do Brasil, do seu substrato tupi-guarani, das influências de outros idiomas aqui trazidos e mantidos pelas coletividades bem como das línguas africanas dos tempos coloniais" O caráter interdisciplinar não foi esquecido: "A todos oferecemos as páginas da nossa revista bem como aos etnólogos, aos antropólogos, aos estudioso da sociologia e da psicologia, naquele problemas grandemente relacionados e entrelaçados aos da ciência da linguagem."

A revista estava dividida em várias seções: a) Artigos, b) Filólogos, c) Transcrição, d) Crítica de Livros, e) Revistas, f) Publicações Recebidas e, vez por outra, g) Crônica e Noticiário. Autores.

O índices organizados são dois: Indice de Assuntos e Indice de

O primeiro permitirá ao leitor a localização do tema ou do assunto que está a procura. $O$ outro, organizado por ordem alfabética de autor, contém, logo após o título do artigo, pequeno resumo do estudo indicado.

$\begin{array}{lrrll}\text { (1) } 1953 & \text { I } & \text { I } & 1 & \text { julho a setembro } \\ \text { (2) } & \text { I } & \text { I } & 2 & \text { outubro a dezembro } \\ \text { (3) } 1954 & \text { I } & \text { II } & 1 & \text { janeiro a março } \\ \text { (4) } & \text { II } & \text { II } & 2 & \text { abril a junho } \\ \text { (5) } & \text { II } & \text { II } & 3 & \text { iulho a setembro } \\ \text { (6) } & \text { II } & \text { II } & 4 & \text { outubro a dezembro } \\ \text { (7) } 1955 & \text { III } & \text { III } & 1 & \text { janeiro a março } \\ (8) & \text { III } & \text { III } & 2 & \text { abril a junho } \\ (9) & \text { III } & \text { III } & 3-4 & \text { julho a dezembro } \\ (10) 1956 & \text { IV } & \text { IV } & 1 & \text { janeiro a março } \\ (11) & \text { IV } & \text { IV } & 2 & \text { abril a junho } \\ (12) & \text { IV } & \text { IV } & 3-4 & \text { julho a dezembro } \\ \text { (13) } 1960 / 61 & \text { VV } & \text { V } & 1-2 & \end{array}$

INDICE DE ASSUNTOS

ACULTURAÇÃO LINGUISTICA

- teuto-brasileira, II (2): 134-149, III (1): 19-26

\section{ADJETIVOS}

87-106 designativos de tamanho e cor em Petronio, III (2): 


\section{ADSTRATO}

- o. no dialeto paulista, IV (3-4): 1-42

- o tupi como. adstrato no portugues falado no Brasil, $V$ $(1-2): 22-40$

\section{AGREMIAÇÕES}

- Academia Brasileira de Filologia, II (4): 409

- Sociedade de Estudos Clássicos, II (4): 409

\section{ANĀLISE LOOGICA}

— o ensino da ., II (4): 398-402

\section{ANGLICISMOS}

- na vida social, III (3-4): 202-212

- em matéria de bebidas alcóolicas, III (3-4): 213-218

- e problemas de tradução, IV (2): $23-28$ e (3-4): $43-47$

\section{ARQUILOCO}

\section{- $\mathrm{V}$ VERSOS ARQUILÓQUIOS}

ARTE DE TROVAR

- portuguêsa, I (1): 67-74

ASPECTO VERBAL

- o. ., I (2): 135-141

- o. ., em grego, I (2): 139

- o. em latim, I (2): 139-141

- o. em línguas semíticas, I (2): 137-138

- $\quad$ em indo-europeu, I (2): 137-138

— tipos de ., I (2): 138

\section{ARTIGO}

- o. indefinido em portugues, II (1): 23-31

\section{AUTO DAS REGATEIRAS DE LISBOA}

— edição brasileira do ., I (2): 162-170

\section{BILINGISMO}

- no Paraguai e em Corrientes, I (1): 45-58 
BIOGRAFIA. BIO-BIBLIOGRAFIA

- Silvio Romero, I (2): 121-134

- V FILOLOGOS

\section{CALENDÁRIO}

- V ONOMÃSTICA

CANCIONEIRO

- $\mathrm{V}$ TROVADORES

CARNEIRO RIBEIRO (Ernesto)

- a polêmica entre. e Rui Barbosa, III (3-4): 183-201

CASTELO BRANCO (Camilo)

— a linguagem de. ., III (1): 1-18

CERVANTES (Miguel de)

- V QUIXOTE (D.)

CÓDIGO CIVIL

— redação do. - V POLEMICA

CONGRESSOS

- Primeiro Congresso Internacional de Dialetologia Geral (Louvain e Bruxelas, 1960), V (1-2): 71

- Primeiro Congresso de Dialetologia e Etnografia (Porto Alegre, 1955), IV (3-4): 102-110

CONSONATISMO

- influência italiana na fala de São Paulo, I (1): 6-8

CRIOLO

- V CURAÇAU

CURAÇAU

- o papiamento em. ., IV (1): 53-60

DANÇA MACABRA

— origem da. ., III (3-4): 227-238 


\section{DIALETOLOGIA. DIALETOS}

- papiamento em Curaçau, IV (1): 53-60

- V FALAR REGIONAL

- dialeto paulista, IV (3-4): 142

\section{DICIONĀRIO}

\section{- V PORTUGUES-ARCAICO}

\section{DOUTORAMENTO}

- de Dinorah da Silveira Campos Pecoraro - tese: "A vida de Santo Aleixo", I (2) : 195

- de Isaac Nicolau Salum, em Filologia Românica - tese: "Contribuições linguísticas do litim cristão na România antiga" II (4): 408

- de Armando Tonioli, em Língua e Literatura Latina-tese: "Adelphi”, II (4) : 408-409

\section{EMPRESTIMO}

- de sentido na românia ocidental, I (1): 17-28

- Africanismos no Brasil. II (3): 217-231

- Italianismo no Brasil, I (1) : 3-16

- Tupinismos no Brasil, I (2): 109-120, V (1-2): 22-40

- V ACULTURAÇÃO LINGUISTICA

- V SUBSTRATO LINGUISTICO

\section{ESTILISTICA}

— o objeto da. ., I (1): 59-62

— estilo de Petronio, III (2): 87-106

- V CASTELO BRANCO (Camilo)

- V LUSIADAS (Os)

\section{EXPRESSÕS POPULARES}

- modismos e. de origem tupi, I (2): 116-119

FALAR REGIONAL

- de São Paulo, I (1): 3-16, IV (3-4): 1-42

— do Vale do Itajai, II (2): 134-149, III (1): 19-26

FIDALGUIA

- crise da

- V CERVANTES 


\section{FILOLOGIA ROMÂNICA}

- latim vulgar na Espanha, III (2): 81-86

— o s final na românia, II (3): 272-280

— os dias da semana naslínguas românicas, III (2): 81-86

- V ROMĀNIA OCIDENTAL

\section{FILOLOGOS}

- Amado Alonso, I (2): 196-197

- Ambrogio Ballini, II (3-4) : 80-83

- Américo Brasiliense Antunes de Moura, II (1): 97-101, IV (1): 61-66

— Eduardo Carlos Pereira, II (3): 281-287

- Fausto Barreto, IV (2): 46-52

- Giogio Pasquali, I (2): 197-198

- Heráclito Graça, III (2): 135-141

- Jakob Jud, I (2): 196

- Júlio Ribeiro, II (1): 58-65

- Manuel Said-Ali, II (1): 102-104

- Mário Barreto, II (4): 394-397

- Maximiniano de Araujo Maciel, III (1): 75-78

- Oscar Nobiling, I (2): 153-161

- Oswaldo Pinheiros dos Reis, III (3-4-: 239-242

- Otoniel Mota, I (1): 63-66

- Rui Barbosa, IV (3-4): 69-79

- Serafim da Silva Neto, V (1-2): 53-54

- Sever Pop, V (1-2): 73-74

— Silvio de Almeida, II (2): 188-198

FOLCLORE

- os estudos de. por Silvio Romero, I (2):129-133

FONEMA

- V EVOLUÇÃO FONETICA

FONETICA

— evolução. ., I (2): 142-145

- V influência italiana na fala de São Paulo, I (1): 6-8

- V papiamento em Curaçau, IV (1): 53-57

GIRIA JORNALISTA

- V IMPRENSA 


\section{GREGO}

- aspecto verbal em. ., I (2): 139

— substrato e linguagem médica, II (4): 313-327

\section{GRAMATICA}

- a linguística e a ., I (2): 89-108

- problemas gramaticais da polemica entre Rui Barbosa e Carneiro Ribeiro, III (3-4): 190-201

HISTÓRIA. HISTORIOGRAFIA

- e literatura, II (2): 113-121

IDADE MEDIA

- espanhola, V MIO CID

- alemã, V LÍRICA MEDIEVAL

\section{IMIGRAÇĀO}

- germânica, V FALAR REGIONAL do Vale do Itajaí - italiana, V FALAR REGIONAL de São Paulo

IMPRENSA

— a linguagem da ., II (1): 48-57

INDIANISTAS

- V FILÓlOGOS: Ambrogio Ballini e Francesco Ribezzo

JERÔNIMO (São)

— as fontes escritas de ., III (3-4): 165-176

JULIO CESAR (Caio)

— arte poética. ., II (3): 250-255

JUSTAPOSIÇĀO

— estudo sobre a ., III (2): 107-112 


\section{LATIM}

- vulgar na Hispania, III (2): 81-86

— aspecto verbal em ., I (2): 139-141

- traduções latinas e formação da prosa portuguesa, II (1): $32-40$

LINGUA (S)

— influência externa na ., I (2): 100-103

- caráter social da ., V LINGUISTICA E GRAMÂTICA

- mutabilidade das ., I (2): 96-99

- V DIALETOLOGIA

- V FALARES REGIONAIS

- $V$ GREGO

- V INDO-EUROPEU

- V LATIM

- V PAPIAMENTO

- $\mathrm{V}$ PORTUGUES ARCAICO

- V PORTUGUES FALADO NO BRASIL

$-\mathrm{V}$ TUPI. TUPI-GUARANI

- $\mathrm{V}$ SEMITICAS

\section{LINGUAGEM}

- da imprensa, II (1): 48-57

- e sociedade, II (1): 66-75 e (2): 177-187

- médica, II (4): 313-327

- língua e ., II (1): 66-75 e (2): 177-187

- psicologia da ., idem

\section{LINGUISTICA}

— V L gramática, I (2): 89-108

\section{LIRICA}

- espanhola, V MIO CID

- medieval elemã, I (2): 146-152

- V AUTO DAS REGATEIRAS

- V ARTE DE TROVAR

\section{LITERATURA}

- alemã medieval $-V$ TROVADORES

- brasileira, V SILVIO ROMERO

- e história, II (2): 113-121 
- epanhola - V MIO CID, QUIXOTE

- grega, $\mathrm{V}$ VERSIFICAÇAO

- latina, $v$ JULIO CESAR, PETRONIO

- patristica, $v$ JERONIMO (São)

- portuguesa, $V$ ARTE TROVAR; AUTO DAS REGATEIRAS DE LISBOA; LUSIADAS (Os)

\section{LITURGIA}

- responso de Santo Antonio, I (2): 169-170

LUSIADAS (Os)

- influências vergilianas em ., IV (2): 1-22

METRICA

- grega, $\mathrm{V}$ AROUILOGO

- latina, $V$ JULIO CESAR

MIO CID

— a religiosidade no Poema de. ., II (2): 150-171

MORFEMA

- e semantema, III (2): 128-134

MORFOLOGIA

- e sintaxe, III (3-4): 177-182

- V ARTIGO

- aspectos da. do dialeto palista, IV (3-4): 16-20

NACIONALISMO

- V SILVIO ROMERO

NOVELA DE CAVALARIA

-V QUIXOTE

- V MIO CID

\section{ONOMASTICA}

- e calendário, IV (1): 1-35

— denominações geográficas em Portugal, V (1-2): 1-21 
PAPIAMENTO

- de Curaçau, IV (1): 53-60

PARTICULAS MODAIS

— V JUSTAPOSIÇÃO

PETRONIO

— o estilo de ., III (2): 87-106

POESIA

- espanhola, V MIO CID

- grega, V VERSOS ARQUILOQQUIOS

- latina, V JÚLIO CESAR

POETAS

- V JULIO CESAR

- V ARQUILOCO

POLEMICA

- a entre Rui Barbosa e Ernesta Carneiro Ribeiro, III $(3-4): 183-201$

PORTUGUES ARCÃICO

— dicionário de ., II (1): 41-47, (2): 172-176, (3): 265271, (4): 370-377, III (1): 43-54, (2): 113-127, (3-4): 219-226; IV (1): $36-52$, (2): 29-37, (3-4): 49-63; V (1-2): $41-52$

PORTUGUES FALADO NO BRASIL

- V ANGLICISMOS

- Dialeto paulista, IV (3-4): 1-42

— influência das línguas africanas no. ., II (3): 217-231

- influência do tupi no. ., I (2): 109-120, III (1): 27-32, $\mathrm{V}(1-2): 22-40$

— influência italiana na fala de São Paulo, I (1): 3-16

- linguajar teuto-brasileiro, I (1): 29-44; II (2): 134-149, III (1) : $19-26$ 


\section{PROSA PORTUGUESA}

— as traduções latinas e a formação da. ., II (1): 32-40

PROSÓDIA. PRONUNCIA

— influência italiana na. da fala de São Paulo, I (1): 6-8

- dos verbos em quai e guai, IV (3-4): 64-68

\section{PSICOLOGIA}

- no estudo da linguagem, II (1): 66-75; (2): 177-187

\section{QUIXOTE (D.)}

— estudo sobre o primeiro capítulo de. ., II (4): 328-363

\section{RELIGIĀO}

- V LITURGIA

—a religiosidade no "Poema de Mio Cid", II (2): 150-171

\section{RENASCIMENTO}

- em Portugal - V LUSIADAS (Os)

ROMĀNICA OCIDENTAL

— unidade semântica de ., I (1): 17-28

— o s final na românica, II (3): 278-280

- V FILOLOGIA ROMÂNICA

- V LATIM VULGAR

\section{ROMANTISMO}

— conceito de por Silvio Romero, I (2): 127-129

- V SILVIO ROMERO

- V CASTELO BRANCO (Camilo)

\section{RUI BARBOSA}

- a polêmica entre e Ernesto Carneiro Ribeiro, II (2): 122-133, (3): 236-249; III (1): 33- 42, (3-4): 183-201

- bio-bibliografia do conselheiro ., IV (3-4): 69-79 
SEMANTICA

- unidade da românia ocidental, I (1): 17-28

SEMITICAS (Línguas)

- o aspecto verbal nas ., I (2): 137-138

SILVIO ROMERO

— pensamento romântico e nacionalista de ., I (2): 121-134 SIMBOLOS. SIMBOLOGIA

- V SINAIS

\section{SINAIS}

— a linguagem e seus ., II (4): 364-369

\section{SINTAXE}

— influência italiana na sintaxe da fala de São Paulo, I (1): 13-16

- a influência tupi e a sintaxe do portugues do Brasil, I (2): 119-120

- morfologia e ., III (3-4): 177-182

- do dialeto paulista, IV (3-4): 24-27

\section{SISTEMA VERBAL}

- o aspecto e o tempo no ., I (2): 135-141

\section{SUBSTRATO}

- como atua o linguístico, IV (2): 38-45

- grego e linguagem médica, II (4): $313-327$

-o guarani e o dialeto paulista, IV (3-4): 27-28

\section{SUPERSTRATO}

- línguas africanas como em relação ao portugues do Brasil, II (3) : 217-231

- o espanhol e o dialeto paulista, IV (3-4): 29-31

- 0 africano e o dialeto paulista, IV (3-4): $31-33$

\section{TOPONIMIA}

- V ONOMÁSTICA 
TRADUÇÃO

- do inglês para o português, IV (2): 23-28, (3-4): 43-47

- traduções latinas e formação da prosa portuguesa, II (1): $32-40$

TROVADOR. TRAVADORISMO

- arte de provar portuguêsa, I (1): 67-74

- cantigas do rei Henrique, I (2): 146-152

TUPI. TUPI-GUARANI

- influência do tupi no portugues do Brasil, I (2): 109-120, V (1-2): $22-40$

- no litoral paulita, III (1): 27-32

- V BILINGUISMO

UM (A)

- V ARTIGO INDEFINIDO

VERBO

- $V$ SISTEMA VERBAL

$-\mathrm{V}$ ASPECTO

— forma de conjugação apropringua e míngua, III (1): 68-71

VERGILIO

- V LUSIADAS (Os)

VERSIFICAÇĀO

- $V$ ARTE DE TROVAR

- V AUTO DAS REGATEIRAS DE LISBOA

- $\mathrm{V}$ TROVADOR

- $\mathrm{V}$ VERSOS ARQUILÓQUIOS

VERSOS ARQUILOQUIOS

— os ., II (1): 1-22

VOCABULÁRIO

- paulistano e influência italiana, I (1): 3-16

- $\quad$ regional de São Paulo, IV (3-4): 1-42

- $\quad$ teuto-brasileiro, II (2): 143-149 


\section{VOCÁBULOS}

- $\quad$ gregos e linguagem médica, II (4): 313-327

- de origem africana em uso no Brasil, II (3): 227-231

- de origem norte-americana em uso no Brasil. III (3-4): 202-212

- de origem tupi em uso no Brasil, I (2): 112-116

- ocorrência de italianos no português falado em São Paulo, I (1): 9-16

— uso de alemães no Brasil, I (1) : 28-44

- $\mathrm{V}$ ANGLICISMOS

- $\mathrm{V}$ PORTUGUES ARCAICO

VOZ

— produção da normal, II (3): 232-235

\section{INDICE DE AUTORES}

ARNS, Evaristo Paulo

Como redigia S. Jeronimo. III (3-4): 165-167

Anotações sobre as fontes dos escritos desse autor do século IV

AUBRETON, Robert Henri

Os versos arquilóquios. II (1): 1-22

Aplicação aos versos arquilóquios das regras propostas por J Irigoim, dando ênfase ao elemento rítmico nos poemas de Píndaro e Baquílides. No final do artigo o autor escreve:" uma melhor compreensão dos metros empregados abrirá caminho a novos estudos de rítmica para os quais o metricista deveria se desdobrar em músico."

BOSSMANN, Reinhold

Do linguajar teuto-brasileiro. II (2): 134-149

Estudo da aculturação linguística dos imigrantes alemães no sul do Brasil.

BUENO, Francisco da Silveira

Influência italiana na fala de São Paulo. I (1): 3-16

Após breves informações sobre a imigração italiana, o autor afirma que "nem o italiano aprendeu o português, nem o paulista aprendeu o italiano: ficaram ambos a falar esse terceiro tipo de 
dialeto - a fala do Brás, a fala de São Paulo" (p. 16). A seguir estuda a influência italiana a partir da fonética - (p. 6-7), do vocabulário (p. 9-13) e da morfologia e sintaxe (p. 13-16)

Influência do tupi no português do Brasil. I (2): 109-120

Estudos das influências da língua tupi na fala rústica do brasileiro, do ponto de vista fonético, vocabular e morfo-sintático. $\mathrm{O}$ autor afirma à p. 111: "a influência do tupi-guarani na lusitanização da nossa pátria foi muito grande e até hoje ainda não foi posta em seus devidos termos porque somente agora começam tais estudos a ser feito com bases científicas"

Uma leitura acurada permite ao leitor entrever que neste artigo as tais bases científicas não foram plenamente atingidas.

O problema do artigo indefinido em português. II (1): 23-31.

Estudo, refutando Leite de Vasconcelos, da formação do feminino uma, derivado de um.

Influências das linguas africanas no português do Brasil. II (3): 217-231

O autor primeiro analisa, com brevidade, as resultantes linguísticas dos contatos entre negros e brancos. Cuida, utilizandose de numerosos exemplos, do yeismo ("não há fundamento para atribuir-se ao elemento negro o yeismo da fala rústica brasileira"), da assimilação da palatal $\mathrm{j}$ na africada sonora $\mathrm{z}$, da dissimilação (" já vem do latim vulgar. muito antes de qualquer influência negra"), da aférese, da apócope, do racismo do surabact, do vocabulário. Silveira Bueno discorda de Renato Mendonça .

Observações filológicas à linguagem de Camilo. III (1): 1-18

Estudo especial do vocabulário e da sintaxe.

Carneiro versus Ruy. III (3-4): 183-201.

O autor analisa a importância da "Réplica" e da "Tréplica" para os estudos de línguas portuguêsa. Dá a Ernesto Carneiro Ribeiro o seu devido valor como cultor da língua. Não poucas vezes o articulista indica os deslizes e menor probidade de Rui Barbosa nas citações.

Influência vergiliana em 'Os Lusiadas'L IV (2) : 1-22.

Diz o autor: "Muito viva é a influência de Vergílio em Camões, estando quase sempre ante seus olhos os episódios, os re- 
cursos de técnica literária da Eneida, o grande modêlo de " $O s$ Lusíadas" Ambos (Camões e Vergílio) são os cantores do patriotismo, do nacionalismo e ambos os poemas atestarão a todos séculos futuros o que pode construir a inspiração da pátria nos lábios dos gênios."

\section{$O$ dialeto paulista. IV (3-4): 1-42.}

Estudo da variante do português falado na interlandia paulista, que está fadado a desaparecer. No final do artigo são estudadas as "causas da dialetação de São Paulo", o substrato guarani, o tipo da língua portuguesa, o superstrato espanhol, o superstrato africano.

Le tupy et le guarany et le portugais du Brésil. V (1-2): $22-40$.

Análise das condições de como as duas línguas atuaram como adstrato no português falado no Brasil.

CÂMARA Jr., Joaquim Mattoso

Morfologia e sintaxe. III (3-4): 177- 182.

Discussão sobre a distinção entre morfologia e sintaxe, tendo em conta principalmente a postura saussuriana.

CASTRO, Américo

O papiamento de Curaçau. IV (1): 53-60

Adição aos estudos de fonética contidos no trabalho de Rodolfo Lenz ('El papiamento, la lengua criolla de Curaçáo'), com breve referência à influência do castelhano $\mathrm{e}$ ao descrioulamento.

CRETELLA Jr. José

Dicionário de português arcáico.

II (1): 41-, a-aaz

II (2): 172-176, aazador-aberregar-se

II (3): 65-71, abesso-acá

II (4): 370-377, acaa-achãado

III (1): 43-54, achaacer-adevinhança

III (2): 113-127, adevinhar-a fundo

III (3): 219-226, agardar-al

IV (1): 36-52, Alá-apassionado 
IV (2): 29-37, apocima-ajusto

IV (3-4): 49-63, ar-aturar

V (1-2): 41-52, auga-azu

Reunião de vocábulos extraídos principalmente das cantigas dos trovadores e da obra de Gil Vicente.

$A$ arte poética de Caio Julio Cesar. II (3): 250-255.

Anotaçōes sobre a poesia de Julio Cesar a partir de seis hexâmetros transcritos por Suetonio em Vida de Terêncio.

$O$ objeto de estilística. I (1): 59-62.

Nota sobre a conceituação de estilística o que permitirá compreender seus limites.

O aspecto e o tempo no sistema verbal. I (2): 135-141 .

Breve estudo da noção de aspecto e noção de tempo, buscandoexemplificação no indo-europeu e línguas semíticas, no grego e no latim.

\section{CRUZ-CORONADO, Guillermo}

El caballero andante - sobre el primer capitulo del Qui jote. II (4): 328-363.

A partir da afirmação: "Estes hidalgos de la Edad Moderna son restos, no assimilados, de actitudes espirituales de una sociedad pasada.." (p. 328), o autor discorre sobre "la crisis da hidalguia y la fuja de la cabelleria"

\section{ELIA, SILVIO}

Justaposição. III (2): 107-112.

Estudo da realização linguística das orações justapostas e subordinadas, em particular na língua portuguesa.

FIGUEIREDO, Fidelino de

Conhecimento histórico e conhecimento literário. II (2): 113-121.

Pondera o autor: "Ambas as formas de conhecimento, a histórica e a literária, são na sua essência uma recuperação do passado por meio dos vestígios dêle: os documentos. $O$ conhecimento 
literário é acompanhado de emoção estética, mas esta não é impossível, nem rara no conhecimento histórico, por feito da grandeza dramática dos sucessos ou da superior beleza da obra historiográfica, em que estão narrados."

GEMELLI, Agostinho - ZUNINI, Giorgio

O p.d.v. da psicologia no estudo da linguagem. II (1): 6675/ II (2): 177-187

Tradução do capítulo décimo da Introduzione alla Psicologia (Milão Coc. Ed. Vita e Pensiero, 1949)

Estudo dividido em 4 partes: a) O problema, b) Língua e linguagem, c) A análise psicológica da linguagem, e d) linguagem e sociedade.

GUERIO, R. F Mansur

Alguns caracteres da evolução fonética. I (2): 142-145.

Breve estudo da irreversibilidade, da reversibilidade, de constância ou regularidade e da simultaneidade na evolução fonética.

A linguagem e seus sinais. II (4) : 364-369.

Breve estudo sobre o sinal linguístico, combinação do significado com o significante.

LIMA, Mário P de Sousa

$O$ pensamento romântico e racionalista de Silvio Romero. I (2): 121-124.

Estudo da trajetória e evolução do pensamento literário do crítico sergipano. O autor afirma que Silvio Romero procurou realizar seu ideal (que sempre foi de um Brasil autônomo, independente na política e mais ainda na literatura) e seu sonho ("Independência literária, independência científica, independência política do Brasil, eis o sonho de minha vida")

MAUER Jr., Theodoro $\mathrm{H}$.

Unidade semântica da românia ocidental os empréstimos I (1) : 17-28 .

Diz o autor: " para se avaliar em toda sua extensão a unidade do vocábulo românico é preciso examinar a semelhança de 
significação das mesmas palavras nas diversas línguas do grupo, mesmo quando o sentido moderno é recente" (p. 17) E prossegue: "Naturalmente não pretendemos que esta concordância na renovação semântica do seu vocabulário seja o fato mais decisivo para estabelecer a unidade linguística que estamos investigando"

A linguística e a gramática. I (2): 89-108.

O artigo está dividido em três partes principais: 1) a língua se transforma, 2) a língua sofre influências estrangeiras, 3) a língua não se atem a formas lógicas de expressão. Após considerações sobre o conceito e o objeto da gramática e da linguística o autor termina por ponderar: " é essencial nunca perder de vista o caráter social da língua e a importância fundamental do uso consagrado com seu poder coercitivo inevitável em todas as questões de boa linguagem. Essa é a lição que a linguística pode trazer à obra dos gramáticos"

MOREJÓN, Julio Garcia

La religiosidad en el "Poema de Mio Cid" II (2): 150-171

Análise do espírito religioso presente na Idade Média espanhola . Quando à religiosidade no "Poema de Mio Cid" diz o autor: "Pero no obstante toda la enorme religiosidad que destila el Cantar, no nos encontramos ante um obra puramente religiosa, ni ética, sino ante algo especialmente personal que se convierte en asunto del Poema; porque del Cid, de su honra y de su gloria, es delo que en él se trata."

OROZ, Rodolfo

Estudo dos recursos estilísticos que caracterizam a "linguagem" de Petronío através dos meios de intensificação e do uso de adjetivos (magnus, grandis, ingens, enormis e os designativos de cores).

PAULA MARTNIS, Maria de Lourdes de

Pakovaty. Nota de viagem. III (1): 27-32. falada.

Notas sobre um grupo Guarani de Peruíbe e a língua por ele

PAXECO, Elza

Arte de trovar portuguesa. I (1):67-74 
Estudo que diz respeito à nova maneira de ler e de interpretar a "Arte de trovar" portuguesa. Cuida das novas interpretações de expressão moz dobre e dos vocábulos petiz, e lez.

PECORARO, Dinorah da J C.

Astraduções latinas e a formação da prosa portuguesa. II (1) : $32-40$.

A autora apresenta como principal razão do grande número de traduções latinas o latim não só como fonte dos assuntos mas também o modelo da língua e da forma literária. Trtta-se do Capítulo I de "A vida de Santo Aleixo", tese de doutoramento.

Algumas considerações sobre a produção da voz normal e na ausencia da laringe. II (3): 232-235.

Considerações sobre os elementos fisiológicos e anatómicos que interferem na produção da voz.

PHILIPSON, Jum Jacob

La enseñanza del guarani como problema de bilinguismo. I (1): 45-58 .

O autor primeiramente estuda os casos e espécies do bilinguismo para depois fazer ponderações sobre a situação do guarani no Paraguai e na província de Corrientes (Argentina), estribando-se principalmente em investigaçōes de Marcos A. Morinigo e de Saturnino Muniagurria.

PIDAL, R. Menendez

Como atua o substrato linguístico. IV (2): 38-45.

Análise das condições de como uma língua adotada por um povo sofre influência daquela que antes era falada por esse mesmo grupo. Dá anfase à ação retardada do substrato .

PINTO, Pedro A.

Linguagem médica. Notas de estudo. II (4): 313-327

Notas acerca da prosódia e significado de alguns vocábulos: nostalgia, arrostia, ergasiodermatese, termofagia, biofagia, empsifagia, etc. 
POLITZE, Robert L.

O s final na românia. II (3): 272-280.

Diz o autor: "Uma real evidência exclui a perda arcaica do s final como base satisfatória para a disbtibuição românica que pode ser melhor compreendida pela consideração das forças culturais e sociais que atuaram na formação individual das línguas românicas no oitavo século"

RAMOS, Dorival Soares

Breves considerações sobre a forma de se redigir para a imprensa. Segue-se um levantamento do vocábulos e expressões mais usuais.

RIBEIRO, Luis da Silva

Breves notas a uma edição brasileira do "Autor das Regateiras de Lisboa" I (2): 162-170.

Estudo da problemática litúrgica a partir dos "Auto da Regateiras de Lisboa", editadas por F. S. Bueno, cuidando especialmente do "responso de Santo Antonio"

ROSENTHAL, Erwin Theodor

As cantigas do Rei Henrique. I (2): 146-152.

Discussão sobre a autoria de cantigas alemãs do século VII.

A, Filipo Franco de

Apropínqua e mingua. III (1): 68-71

Estudo sobre a forma de conjunção.

Agúa, apropingua ou água. IV (3-4): 64-68.

$\mathrm{O}$ autor indica as boas normas para bem pronunciar os vocábulos indicados no título.

SALUM, I. N

Os dias da semana nas línguas românicas. IV (1): 1-35.

O presente trabalho é uma refundição da segunda metade do Capítulo IX da tese de dotourado do autor: $A$ contribuição 
linguística do cristianismo na românia antiga. Dá enfase ao estudo do vocábulo semana (p. 7-19) e aos nomes da tradição grecoromana (p. 19-35)

SAMOS, Silva

Explicar ou complicar?. II (4): 398-402.

Considerações acerca do ensino da análise lógica, sendo o autor contra o uso e ensino indiscriminado de tal análise.

SIVEIRA, Alípio

Norte-americanismo sobre a vida social. III (3-4) : 202-212. Após escrever em brevidade o fenômeno do pioneirismo 213-218

nos E.U. o autor analisa os vocábulos de origem norte-americana que tem uso corrente no Brasil.

Anglicismo em matéria de bebidas alcoólicas. III (3-4):

Breve estudo dos anglicismos correntes no Brasil.

Como se traduz o ingles para o nosso idioma. IV (2): 2328 / IV (3-4): 43-47

Estudo dos priblemas que surgem da necessidade de se traduz texto do inglês para o português.

\section{SCHADEN, Egon} 29-44.

Aculturação linguística numa comunidade rural. I (1):

Estudo de alguns aspectos da aculturação linguística de imigrantes germanicos habitantes do vale do rio Capivari (Santa Catarina), dando enfase aos aspectos vocabulares. Publica vocabulário recolhido, em 1942, entre os habitantes de S. Bonifácio.

SOUSA, Arlindo de

Origens históricas e filologicas, de expressão popular, de algumas povoações e locais. V (1-2): 1-21.

Considerações em torno das denominações geográficas de aglomerados urbanos em Portugal. 
STELLA, Jorge Bertolaso 256-264.

Os estudos de Francesco Ribazzo (1875-1952) II (3):

Biografia e bibliografia do filólogo italiano, dando enfase aos seus trabalhos de natureza teológica.

STRINGARI, $\mathbf{P}$

Pesquisas linguísticas regionais. III (1): 19-26.

Considerações em torno de pesquisa levada a efeito em área de colonização tirolesa no vale do Itajaí.

TORRES, Artur

Comentários sobre a polêmica entre Rui Barbosa e Carneiro Ribeiro. II (2): 122-133 / II (3): 236-249 / III (1): 35-42.

Exame da memorávelı polêmica a partir da segunda parte da Réplica, porque foi ai que Rui Barbosa entrou na análise das críticas formuladas por Carneiro Ribeiro, através de suas "Ligeiras Observações"

TOVAR, Antonio

Latim vulgar, latim de Hispania. III (2): 81-86.

Após considerações aspectos gerais sobre o latim vulgar da Hispania termina por afirmar: " Es decisivo para la formación de las lenguas de nuestra Península que no fueron ninguna de las capitales y populosas ciudades romanas las que dirigieran la historia en la alta Edad Media, pero fueron los reconquistadores que de Norte a Sur extendieron las bárbaras características de los mal romanizados."

VENDRYES, $J$.

Semantema e morfema. III (2): 128-134.

Ensina o autor: "A distição do semantema e do morfema repousa essencialmente no fato de que, em toda representação, desde que seja uma ffrase, há possibilidade de distinguir os elementos da representação e a maneira pela qual tais elementos são colocados em relação entre si; ou em outros termos, de uma parte os objetos de que se diz alguma coisa e de outra parte os meios pelos quais se diz aquilo que se quer dizer." 
$-392-$

VIROLO, Emilio P

Origem da "Dança Macraba". III (3-4): 227-238.

Das conclusões podemos mencionar o que se segue: "No século XIV, por causa da grande quantidade de motivos fúnebres, de origem meditativa e real e por influxo de elementos gramáticos análogos, se formou no seio da igreja, a Dança Macraba, em seu restrito seuso, com finalidade sérias de advertir os homens de todas as classes a não colocarem nas efêmeras satisfações terrenas a finalidade de existência, mas a viverem em piedade e justiça, na esperança do prêmio eterno e no pavor do eterno castigo"

ANA SANCHES
21071821 